\title{
Design and site-directed compartmentalization of gold nanoclusters within the intrasubunit interfaces of ferritin nanocage
}

\author{
Jiachen Zang ${ }^{1}$, Bowen Zheng ${ }^{1}$, Xiuqing Zhang ${ }^{1}$, Paolo Arosio $^{2}$ and Guanghua Zhao ${ }^{1 *}$ (]
}

\begin{abstract}
Background: Protein nanocages have emerged as popular nanocarriers for either drug delivery or biotemplates for the preparation of nanomaterials. However, only three interfaces, namely exterior surface, intersubunit and inner cavity, have been used as reaction sites for the above purposes with all known protein nanocages. On the other hand, how to control the site of Au NCs formed within a targeted protein template while maintaining the functionality of protein itself remains challenging.

Results: In this work, inspired by compartmentalization in living systems, we firstly come up with the conception of "intrasubunit interfaces", located within subunit of protein nanocage. We built a new, specific compartment for fabrication of gold nanoclusters by genetic modification of the inherent ferroxidase center located within four-a-helix bundle of each ferritin subunit. This newly built compartment not only realizes the site-directed synthesis of gold nanoclusters but also has no effect on the functionality of ferritin itself such as encapsulation by its inner cavity. These redesigned composites can be further applied as fluorescent imaging agent and carriers for preparation of hybrid nanomaterials.
\end{abstract}

Conclusions: The designing strategy of intrasubunit interfaces opens a new way for future applications of cage-like proteins.

Keywords: Compartmentalization, Intrasubunit interface, Interface redesign, Gold nanoclusters, Mitochondrial ferritin

\section{Background}

Compartmentalization is a hallmark of living systems, which enables them not only to establish physical boundaries for the spatial separation of incompatible or opposing reagents to avoid mutual destruction, but also to perform the chemical reactions between these reagents simultaneously $[1,2]$. Protein nanocages, a class of naturally occurring compartments, shield their cargo from the

\footnotetext{
*Correspondence: gzhao@cau.edu.cn

1 Beijing Advanced Innovation Center for Food Nutrition and Human Health, College of Food Science \& Nutritional Engineering, Beijing Key Laboratory of Functional Food from Plant Resources, China Agricultural University, Beijing 100083, China

Full list of author information is available at the end of the article
}

influence of external conditions and provide a controlled microenvironment. These protein nanocages are widely distributed in nature to fulfill a variety of functions [3-8]. Recently, the protein nanocages have received considerable attention from researchers in the field of nanoscience and nanotechnology due to their valuable properties such as high symmetry, solubility and stability, monodispersity, and ease of genetic and chemical manipulation. Therefore, these protein nanocages have been explored as biotemplates for the preparation of inorganic and organic nanomaterials, and the encapsulation and delivery of guest molecules with various potential applications [3, 4]. Although the protein nancages are markedly different from each other in size, assembly, and function, there 
is one structural feature in common among all reported protein nanocages, namely all of them have three distinct interfaces: the interior, the exterior and the intersubunit interface, as previously reported [3]. However, in this paper, to further develop the application efficiency of protein nanocage, namely build a new compartment within the cage shell for other nanomaterials, we come up with the fourth interface as "intrasubunit interfaces" at the first time (Fig. 1a).

Among these protein nanocages, the ferritin nanocage is unique in that it exhibits high selectivity for human cancer cells which overexpress two kinds of receptors for ferritin $[9,10]$. Thus, it has emerged as a class of drug delivery vehicles and imaging agents. Ferritin ubiquitously occurs in animals, plants and bacteria, and plays a significant role in iron storage and detoxification [11]. It is a nearly spherical 24-subunits-protein with exterior diameter about $12 \mathrm{~nm}$ and a hollow cavity of $8 \mathrm{~nm}$ [12]. Owing to its cage-like morphology and highly symmetrical structure, ferritin displays outstanding thermal and chemical stability and it is remarkably amenable to $\mathrm{pH}$ induced dis- and re-assembly [13, 14]. Like other protein nanocages, ferritins also have four chemically distinct interfaces where can be manipulated in order to impart functionality by design (Fig. 1a). The intersubunit interfaces in ferritin consist of $C_{2}, C_{3}, C_{4}$, and $C_{3}-C_{4}$ as shown in Additional file 1: Figure S1. Among these intersubunit interfaces, $C_{3}$ and $C_{4}$ are mainly responsible for diffusion of small molecules into ferritin cavity $[15,16]$, while $C_{2}$ plays a key role in protein shell assembly [17]. The $C_{3}-C_{4}$ is the most largest intersubunit interface in ferritin, which controls protein geometry based on our recent studies $[18,19]$. To extend the utilization of ferritin nanocage, protein exterior surface has been frequently modified so that it can be endowed with new functionalities such as specific targeting ability or luminescence [20-22]. As popular as the exterior surface, the inner cavity of ferritin has been explored to encapsulate various cargoes such as simple metal ions and complicated drugs [23-25]. However, so far, there have been no reports focusing on the intrasubunit interface of protein nanocages including ferritin prior to this study.

On the other hand, gold nanoclusters ( $\mathrm{Au} \mathrm{NCs)}$ are being actively pursued as a novel kind of fluorescent materials due to their potentially low toxicity, welldefined compositions, bright luminescence and facile surface functionalization [26-28]. After bovine serum albumin (BSA) was first exploited to be embedded with $\mathrm{Au}$ NCs in 2009 [29], substantial proteins have been used as biotemplates for Au NCs synthesis [30-33]. However,

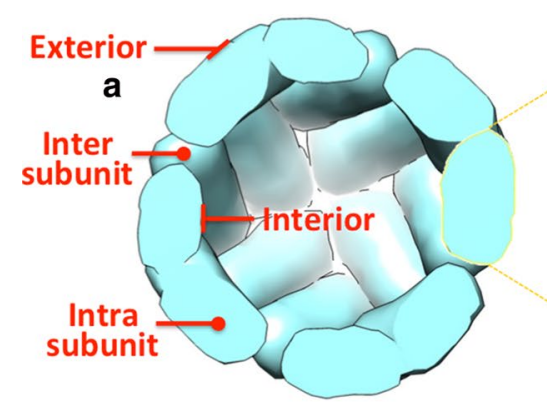

b

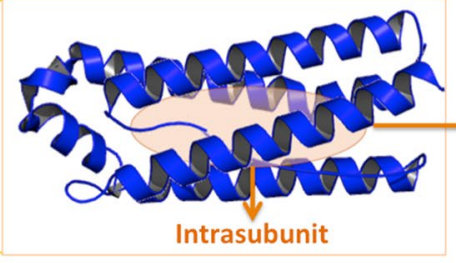

\section{Intrasubunit \\ Interface \\ Redesign}
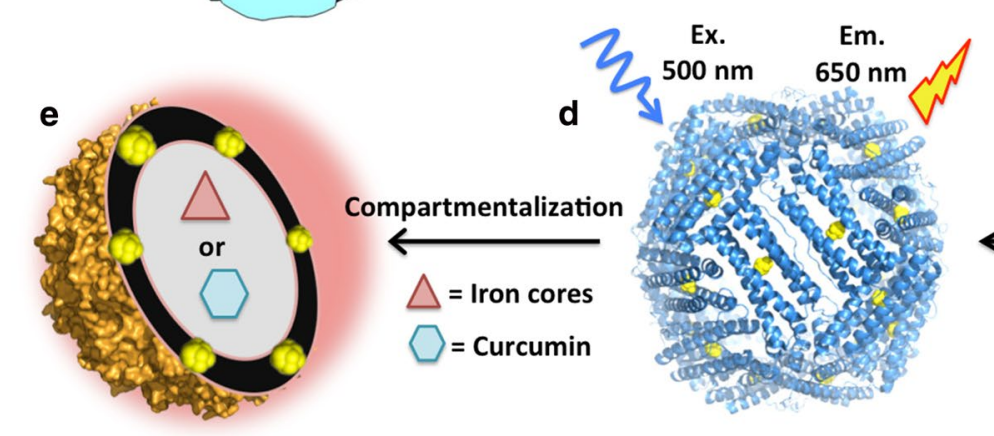

c
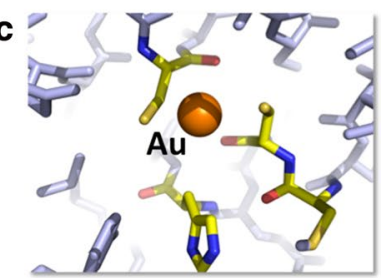

Reduction

Fig. 1 a Structure of ferritin verified by four reacting interfaces, in which the exterior, intersubunit and interior interfaces were reported to be used in a variety of applications. But the intrasubunit interface was put forward for the first time. b Highlight of intrasubunit interface within one subunit. c The ferroxidase center buried within the intrasubunit was redesigned into a new compartment which can specifically bind to gold ions by introducing Cys residues. $\mathbf{d}$ Site-directed synthesis of gold nanoclusters (Au NCs) within 24 four a-helix bundles of one ferritin molecule. e Compartmentalization of two different kinds of nanoparticles within one ferritin nanocage. The Au NCs were located within protein shell, while inorganic iron cores or bioactive organic cargoes were encapsulated within the ferritin inner cavity 
how to control the site and size of Au NCs formed within a targeted protein template while maintaining the functionality of protein itself remains challenging. Herein, we take the compartmentalization concept to re-design the intrasubunit interface of ferritin to create a new compartment for fabrication of fluorescent Au NCs, while keeping the inherent protein cavity functional. Consequently, we can incorporate binary nanomaterials into one ferritin nanocage, namely small Au NCs buried within the intrasubunit and large inorganic or organic nanoparticles (4-6 nm) encapsulated within the cavity, which provide a new way for construction of hybrid nanomaterails.

\section{Materials and methods}

\section{Protein preparation}

cDNA encoding the amino acid sequence of mature HuFtMt was cloned into the pET-3a (Novagen) and verified by DNA sequencing. Mutagenesis of the HuFtMt cDNA was performed with the fast site-directed mutagenesis kit from Tiangen Biotech (Beijing, China). The mutated HuFtMt and wild-type HuFtMt were purified as follows. The E. coli strain BL21(DE3) which contained the expression plasmid was grown at $37{ }^{\circ} \mathrm{C}$. Protein expression was likewise induced with $200 \mu \mathrm{M}$ of isopropyl $\beta$-D-1-thiogalactopyranoside after the cell density reached an absorbance of 0.6 at $600 \mathrm{~nm}$. Then the cells were harvested by centrifugation after $8 \mathrm{~h}$ of induction and resuspended in $25 \mathrm{mM}$ Tris- $\mathrm{HCl}(\mathrm{pH} \mathrm{8.0)}$ to a concentration of $10 \mathrm{~g}$ fresh weight bacteria per liter, followed by disruption by sonication. The supernatant of the resulting crude extract was collected by centrifugation and fractionated by $60 \%$ saturation of ammonium sulfate. The pellet was resuspended in $25 \mathrm{mM}$ Tris $-\mathrm{HCl}$ (pH 8.0) and dialyzed against the same buffer. The protein solution was applied to an ion-exchange column, followed by gradient elution with $0-0.3 \mathrm{M} \mathrm{NaCl}$. Finally, the protein solution was concentrated and purified on a gel filtration column, equilibrated with $25 \mathrm{mM}$ Tris- $\mathrm{HCl}$ and $150 \mathrm{mM} \mathrm{NaCl}$ (pH 8.0). Protein concentrations were determined according to the Lowry method with bovine serum albumin as standard.

\section{Synthesis of ferritin-stablized Au NCs}

Ferritin stablized $\mathrm{Au}$ NCs were synthesized as follows. $200 \mu \mathrm{L}$ of $10 \mathrm{mM}$ aqueous $\mathrm{HAuCl}_{4}$ solution $(\mathrm{pH}$ value tuned to 7.0) was added to a $200 \mu \mathrm{L}$ Tris $-\mathrm{HCl}$ solution containing protein $(50 \mathrm{mg} / \mathrm{mL})$ with vigorous stirring at $37^{\circ} \mathrm{C} .5 \mathrm{~min}$ later, $\mathrm{pH}$ value was adjusted to around 12.8 with further vigorous stirring for $20 \mathrm{~min}$. After that, the mixture solution was incubated at $37{ }^{\circ} \mathrm{C}$ overnight. To increase the storage stability while terminating the reaction, 1.0 $\mathrm{M}$ acetic acid was added drop-wise until the $\mathrm{pH}$ value reached $\sim 7.0$. Resulting products were stored in dark at $4{ }^{\circ} \mathrm{C}$ for further use.

\section{Characterization of ferritin mutants and ferritin-stabilized Au NCs}

UV-vis absorption spectra was recorded by a UV Spectrophotometer (Virian, 50 Bio, USA), and fluorescence studies in a sealed cuvette were carried out with a Fluorescence Spectrometer instrument (Virian, Palo Alto, USA). Fluorescence images were obtained under UVlight. Transmission electron microscope (TEM) images were obtained at $80 \mathrm{kV}$ using a Hitachi S-5500 microscope. High-resolution transmission electron microscope (HRTEM) images were made by a JEM 2100F microscope, and elementary analysis was carried out with Horiba INCA 450 energy dispersive X-ray analysis spectroscopy. The oxidation state of the Au clusters was determined by X-ray Photoelectron Spectroscopy (XPS). Narrow-scan XPS spectra of Au $4 \mathrm{f}$ were deconvoluted by the XPSPEAK software (Version 4.1) using adventitious carbon to calibrate the binding energy of C1s $(284.5 \mathrm{eV})$.

Crystallization, data collection and structure determination Purified proteins were concentrated to $10 \mathrm{mg} / \mathrm{mL}$ in a buffer consisting of $10 \mathrm{mM}$ Tris- $\mathrm{HCl}$ at $\mathrm{pH} 7.6$ and $1 \mathrm{mM} \mathrm{HAuCl}_{4}$. Crystals of wild-type HuFtMt and $\Delta \mathrm{C}$ complexed with $\mathrm{Au}^{3+}$ were obtained using the hanging drop vapor diffusion method by mixing equal volumes of the complex sample and mother liquid, which was composed of $0.1 \mathrm{M}$ Bicine- $\mathrm{NaOH}(\mathrm{pH} 8.5)$ and $2 \mathrm{M} \mathrm{MgCl}_{2}$. Crystals of 2 Cys $-\Delta C$ and 3 Cys- $\Delta C$ complexed with $\mathrm{Au}^{3+}$ were obtained using the hanging drop vapor diffusion method by mixing equal volumes of the complex sample and mother liquid, which was composed of $0.1 \mathrm{M}$ Tris$\mathrm{HCl}(\mathrm{pH}$ 8.5) and 3.4 M 1,6-hexalene glycol. Diffraction data of the crystal were collected at SSRF to resolutions of after flash cooling with $25 \%$ glycerol as a cryo-protectant. Data were processed, merged and scaled with the HKL-3000 (HKL Research). Data processing statistics are shown in Additional file 1: Table S1. The data was determined by molecular replacement using coordinates of wild-type Mfn (PDB code 1R03) as an initial model using the MOLREP program in the CCP4 program package. Structural refinement was conducted using the Refmac 5 program and PHENIX software. The structure was rebuilt using COOT, which made the model manually adjusted. Figures of protein structures were prepared using the PyMOL program.

\section{In vitro and in vivo bioimaging studies}

HepG2 cells were cultured in DMEM supplemented with $10 \%$ (vol/vol) FBS, $2 \mathrm{mM} \mathrm{L}$-glutamine and $1 \%$ penicillin/streptomycin and incubated at $37{ }^{\circ} \mathrm{C}$ with $5 \% \mathrm{CO}_{2}$. 
Briefly, cells were seeded at a density of $3 \times 10^{5}$ on the cell culture dish and pre-incubated for $24 \mathrm{~h}$. Then the cells were treated with RGD decorated 3 Cys $-\Delta C$ and $3 \mathrm{Cys}-\Delta \mathrm{C}$-Au NCs for $3 \mathrm{~h}$ at $37{ }^{\circ} \mathrm{C}$ with $5 \% \mathrm{CO}_{2}$ and then washed by PBS three times. After that, cells were fixed by $4 \%$ paraformaldehyde for $20 \mathrm{~min}$ at room temperature. Last, The confocal laser scanning microscopy was used to image the cells.

Wild-type C. elegans were cultured in the nematode growth medium (NGM) agar plates containing $E$. coli OP50 bacteria (OP50 medium) as food supplement at $20{ }^{\circ} \mathrm{C}$. L4 stage worms were seeded in the NGM agar plates supplemented with $3 C y s-\Delta C$ as negative group and with $3 C y s-\Delta C$-Au NCs as experimental groups. After cultivation for different times, worms were transferred onto microslide smeared with circled albolene and centered $20 \mathrm{mM} \mathrm{NaN}_{3}$ solution to fix the worms and then observed by laser-scanning confocal microscopy. The images of the 3Cys- $\Delta \mathrm{C}$-stabilized Au NCs treated sample and negative control samples were collected in the range of 575-620 nm with $488 \mathrm{~nm}$ as excitation wavelength.

\section{Iron cores formed within $3 C y s-\Delta C$-stabilized Au NCs}

Iron cores within $3 C y s-\Delta C$-stabilized $A u$ NCs were prepared by aerobically adding $500 \mathrm{Fe}(\mathrm{II})$ per protein shell to $3 C y s-\triangle C$-Au NCs solutions in five successive increments of $100 \mathrm{Fe}(\mathrm{II})$ at intervals of $30 \mathrm{~min}$ in $50 \mathrm{mM}$ MOPS at $\mathrm{pH}$ 7.0, followed by standing overnight. After iron loading, the sample was incubated at $4{ }^{\circ} \mathrm{C}$ in dark overnight because the iron mineralization was slower with ferritin mutants where the structure of ferroxidase center had been greatly altered.

\section{Preparation of curcumin-loaded 3 Cys- $\Delta$ C-Au NCs}

Curcumin-loaded 3Cys- $\Delta \mathrm{C}$-Au NCs were prepared as previously reported with curcumin encapsulation by human $\mathrm{H}$-chain ferritin. Briefly, for a $1 \mathrm{~mL}$ system of alkaline as-prepared 3Cys- $\Delta$ C-Au NCs $(1 \mathrm{mg} / \mathrm{mL}$ in $0.15 \mathrm{M} \mathrm{NaCl}$ ), a $200 \mu \mathrm{L}$ solution of curcumin, freshly solubilized in $0.1 \mathrm{M}$ sodium hydroxide $(2 \mathrm{mM})$, was added. Immediately, the $\mathrm{pH}$ value was lowered to 7.5 using $1 \mathrm{M}$ $\mathrm{HCl}$. Resulting solution was stirred at room temperature for $2 \mathrm{~h}$ to promote the assembly of the protein. Finally resultant products were run through a NAP- 5 column to remove free curcumin.

\section{Thermal stability and photostability measurements}

Both of curcumin encapsulated $3 \mathrm{Cys}-\Delta \mathrm{C}-\mathrm{Au} \mathrm{NCs}$ and free curcumin were heated at $60{ }^{\circ} \mathrm{C}$ in a dark tube. The degradation kinetic of curcumin was carried out by scanning UV-vis spectra from 250 to $800 \mathrm{~nm}$ at interval times. In the photostability experiment, the sample for photo degradation studies was placed under an incandescent lamp of $18 \mathrm{~W} / \mathrm{YH}$, at a distance of $10 \mathrm{~cm}$ at $25{ }^{\circ} \mathrm{C}$. the degradation kinetic of curcumin was carried out by also scanning UV-vis spectra from 250 to $800 \mathrm{~nm}$ at interval times. As curcumin is poorly soluble in water, a solution of curcumin dissolved in ethanol at $10 \mathrm{mM}$ was used as stock solution and then diluted to same intensity at $\sim 425 \mathrm{~nm}$ with curcumin encapsulated $3 \mathrm{Cys}-\Delta \mathrm{C}$ - $\mathrm{Au}$ NCs to act as a control sample.

\section{Results and discussion}

\section{Design of ferritin-templated Au NCs}

In this work, we selected the relatively rare reported human mitochondrial ferritin ( $\mathrm{HuFtMt}$ ) nanocage as the protein model based on the following considerations: (1) it is a naturally occurring homopolymer which can simplify the design challenge; (2) its sequence and crystal structural information are available to guide genetic manipulations; and (3) it could be a promising vehicle for tumor imaging and drug delivery due to its nonimmunogenicity. Of particular interest is the site-directed synthesis method of Au NCs (Fig. 1). This involves genetically modifying the ferroxidase center buried within the intrasubunit interface into a compartment which is suitable for growth of Au NCs. To our knowledge this method has never previously been used to 'trap' any NCs and could be implemented to fabricate NCs within the intrasubunit interface of multisubunit protein architectures. More importantly, we demonstrate that incorporation of $\mathrm{Au} \mathrm{NCs}$ into the intrasubunit interface imparts highly luminescent property to ferritin while having no effect on both the formation of inorganic nanomaterials (iron cores) and encapsulation of bioactive molecules (curcumin) within the cavity (Fig. 1e).

$\mathrm{Au} \mathrm{NCs}$ are typically less than $2 \mathrm{~nm}$ in size which approaches the Fermi wavelength of the conduction electrons. Although the cavity of ferritin serves as an ideal nanocontainer for synthesis of various nanoparticles [3, 4], it is not suitable for preparation of Au NCs because the size of the cavity is around $8 \mathrm{~nm}$ in diameter which is too large for such preparation. On the other hand, once the cavity is occupied by Au NCs, the ability of ferritin to encapsulate guest molecules will be greatly compromised. Similarly, it is also difficult to control the size of $\mathrm{Au} \mathrm{NCs}$ on the exterior surface of ferritin. Although the pore size of various ferritin channels (3- or 4-fold channels) located at the intersubunit interfaces (Additional file 1: Figure S1) is similar to that of Au NCs, occupation of these channels by $\mathrm{Au}$ NCs will inhibit diffusion of metal ions into the cavity for mineralization. By investigating all interfaces of HuFtMt, we found that the ferroxidase center buried within the intrasubunit interface appears to meet all kinds of requirements for fabrication of $\mathrm{Au}$ NCs. Firstly, the ferroxidase center is located in the 
middle of four $\alpha$-helix bundle of each subunit, which is some $7 \AA$ from the inside surface of the protein shell and $\sim 12 \AA$ from the exterior surface in a region of considerable hydrophobic character, providing a size-constrained reaction platform for Au NCs synthesis. Secondly, when $\mathrm{Au} \mathrm{NCs}$ were generated at the ferroxidase center, they would not affect the utilization of the ferritin cavity.

Like human $\mathrm{H}$-chain ferritin, the ferroxidase centers of HuFtMt are composed of A and B iron binding sites of conserved amino acid ligands His65, Glu27, Glu107, Glu61 and Glu62 (Additional file 1: Figure S2) [34, 35]. $\mathrm{H}$-bonding residues $\mathrm{Gln} 141$ and Tyr34 are nearby. Besides iron ions, other metals such as magnesium, calcium and zinc can also bind at these centers [36]. To determine whether wild-type (wt) HuFtMt are able to bind to $\mathrm{Au}$ ions, we solved the crystal structure of wt HuFtMt at a resolution of $3.0 \AA$ upon protein treatment with gold ions. The refined structure revealed two $\mathrm{Au}$ ions binding sites where Cys102 and Cys130 are involved in this protein as shown in Fig. 2A1 and B1, demonstrating that $\mathrm{Au}$ ions exhibits the high binding selectivity for cysteine residues. Therefore, to create specific $\mathrm{Au}$ ions binding site at the ferroxidase center, we re-designed these centers by genetically introducing cysteine residues as potential coordination ligands into them under help of the YASARA software in two steps. First, to eliminate

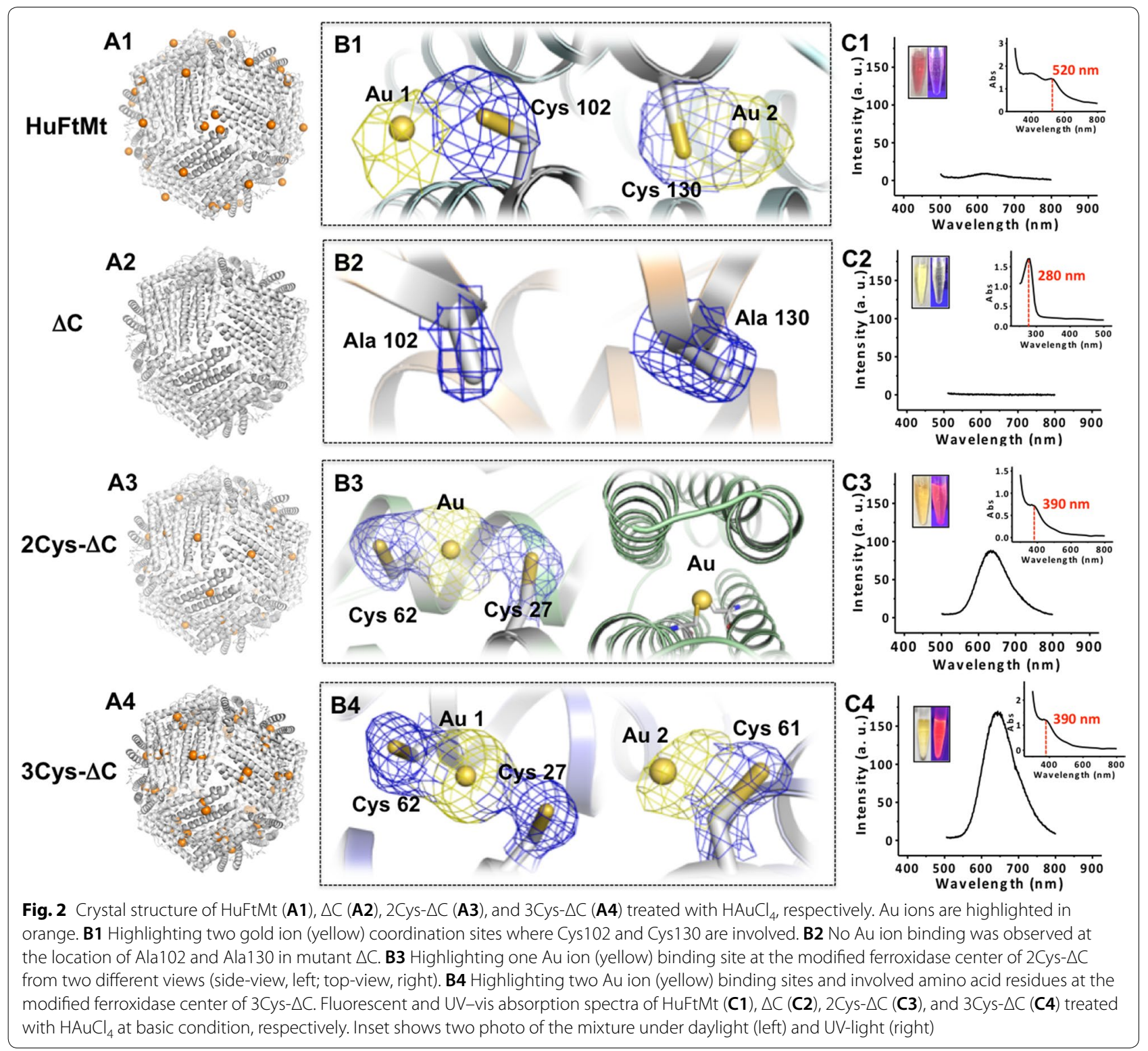


possible non-specific binding of $\mathrm{Au}$ ions, we made a recombinant HuFtMt mutant termed $\Delta \mathrm{C}$ (C102A/ C130A) as a starting plat-form, which is devoid of any cysteine residues. Second, given the binding complexity of gold ions, we prepared a number of the ferroxidase center mutants. We found that both substitution mutants 2Cys- $\Delta \mathrm{C}$ (C102A/C130A/E27C/E61C) and 3Cys- $\Delta \mathrm{C}$ (C102A/C130A/E27C/E61C/E62C) are soluble; in contrast, the majority of two $4 \mathrm{Cys}-\triangle \mathrm{C}$ mutants $(\mathrm{C} 102 \mathrm{~A} /$ C130A/E27C/E61C/E62C/H65C and C102A/C130A/ $\mathrm{E} 27 \mathrm{C} / \mathrm{E} 61 \mathrm{C} / \mathrm{E} 62 \mathrm{C} / \mathrm{Q} 107 \mathrm{C})$ remains in inclusion body pellets even when $0.5 \mathrm{M}$ sorbitol were included in the growth medium, so we focus on the first two mutants.

Genes encoding the designed proteins $(\Delta C, 2 C y s-\Delta C$, and 3 Cys $-\Delta C$ ) were constructed and cloned into an expression vector, Escherichia coli (E. coli) BL21 cells, respectively. After $E$. coli cells expressing the proteins were lysed, the proteins were purified by a combination of gel and ion-exchange chromatography. As expected, SDS-PAGE analyses revealed that all these three mutants consist of one type of subunit (Additional file 1: Figure S3A). Native PAGE of these proteins exhibited a single band, indicating that they were purified to homogeneity (Additional file 1: Figure S3B). As designed, these mutants are indistinguishable from the wt protein in terms of assembly, structure, and morphology based on fluorescence and transmission electron microscopy (TEM) analyses (Additional file 1: Figure S3C and S3D).

It is believed that a small nanocluster in protein scaffolds are formed by binding of metal ions, followed by nucleation [37, 38]. Therefore, we firstly determined whether $\mathrm{Au}$ ions can specifically bind at the modified ferroxidase center. To this end, we obtained the crystals through co-crystallization of three mutants $\Delta \mathrm{C}, 2 \mathrm{Cys}-\Delta \mathrm{C}$ and 3 Cys $-\Delta C$ with $A u^{3+}$, respectively. $\Delta C$ shared a similar method with wt HuFtMt. However, for 2 Cys- $\Delta C$ and 3 Cys- $\Delta \mathrm{C}$, initial co-crystallization trials gave only small crystals, but large single crystals were eventually obtained, which are suitable for X-ray diffraction studies. Subsequently, we solved the crystal structure of these three samples at a resolution of higher than 2.3 $\AA$. As expected, no Au ions binding was observed with $\Delta C$ mutant (Fig. 2A2 and B2) because the inherent binding residues Cys102 and Cys130 in wt ferritin had been replaced by Ala. Differently, the crystal structure of 2 Cys $-\Delta \mathrm{C}$ shows that one gold atom is coordinated by Cys27 and Cys62 in a linear geometry, occupying the original A site of the ferroxidase site, and this $\mathrm{Au}$ ion was buried within four $\alpha$-helix bundle of each subunit (Fig. 2B3). There are totally $24 \mathrm{Au}$ ions occurring at each protein shell as shown in Fig. 2A3. In contrast, two gold atoms are bound at the modified ferroxidase center of each 3 Cys $-\Delta C$ subunit. One atom, named Au1, was located at the site A of the ferroxidase center, which is coordinated by Cys 27 and Cys62 also in a linear geometry, while another gold atom, Au2, interacted with Cys61, nearby site B (Fig. 2B4). Consequently, each 3 Cys $-\Delta C$ molecule can accommodate up to $48 \mathrm{Au}$ ions (Fig. 2A4). Thus, these crystal structures validated our re-design of the ferroxidase center in atomic detail, thereby supporting the utility of the intrasubunit interface strategy for creating the specific Au binding sites.

Subsequently, we determined the ability of these three mutant proteins and wt HuFtMt as biotemplates to synthesize $\mathrm{Au}$ NCs, respectively, following our reported method by mixing protein and $\mathrm{HAuCl}_{4}$ at basic conditions and a further incubation at $37^{\circ} \mathrm{C}$ overnight [32]. Consistent with the above crystal structure results, no fluorescence was observed with $\Delta \mathrm{C}$ due to lack of $\mathrm{Au}$ ions binding in protein molecule (Fig. 2C2). In contrast, the 2Cys- $\Delta \mathrm{C}$-templated $\mathrm{Au} \mathrm{NCs}$ emit a weak fluorescence under the same experimental condition (Fig. 2C3), which has an UV-vis absorbance at $390 \mathrm{~nm}$, which is the characteristic surface plasmon resonance peak of small metal NCs (Fig. 2C3, inset). Among these three mutants, the as-prepared 3Cys- $\Delta \mathrm{C}$-stabilized $\mathrm{Au} \mathrm{NCs}$ emit the strongest red fluorescence at $650 \mathrm{~nm}$ (Fig. 2C4). Thus the crystal structure ensure the Au NCs were synthesized within the subunit, namely intrasubunit.

\section{Characterization of 3 Cys- $\Delta$ C-stabilized Au NCs}

Due to its strongest fluorescence among these three samples, we characterized 3 Cys- $\Delta \mathrm{C}$-stabilized Au NCs with different physico-chemical methods. As shown in Additional file 1: Figure S4, to obtain the strongest emission peak at $650 \mathrm{~nm}$, the maximum excitation wavelength was detected at $500 \mathrm{~nm}$, which is beneficial for its application as an in vivo imaging agent. To illuminate the gold state in the hybrid, we run XPS spectrum with this new type of Au NCs. The $4 f_{7 / 2}$ and $4 f_{5 / 2}$ binding energies were examined, in which, $\mathrm{Au}(0)$ accounts for more than $70 \%$, marked in blue (Fig. 3a). The $\mathrm{Au}(\mathrm{I})$ in red line ranked the second, confirming most of the $\mathrm{Au}(\mathrm{III})$ was reduced to be $\mathrm{Au}(\mathrm{I})$ and $\mathrm{Au}(0)$ during $\mathrm{Au}$ NCs synthesis. The TEM view of 3Cys- $\Delta$ C-stabilized Au NCs showed that Au NCs were monodispersed under basic conditions, while they were associated with each other once $\mathrm{pH}$ was adjusted to neutral (Additional file 1: Figure S5). To characterize the core size, the as-synthesized Au NCs were analyzed by high resolution transmission electron microscopy (HRTEM). According to Fig. 3b, the 3Cys- $\Delta$ C-stabilized Au NCs had spherical shape and were homogeneous in size, which was defined in the range of NCs $(<2 \mathrm{~nm})$. Lattice fringes can be clearly visualized in HRTEM images (Fig. 3b, inset), indicating the formation of nanocrystalline materials. Energy-dispersive X-ray (EDX) analysis confirmed 

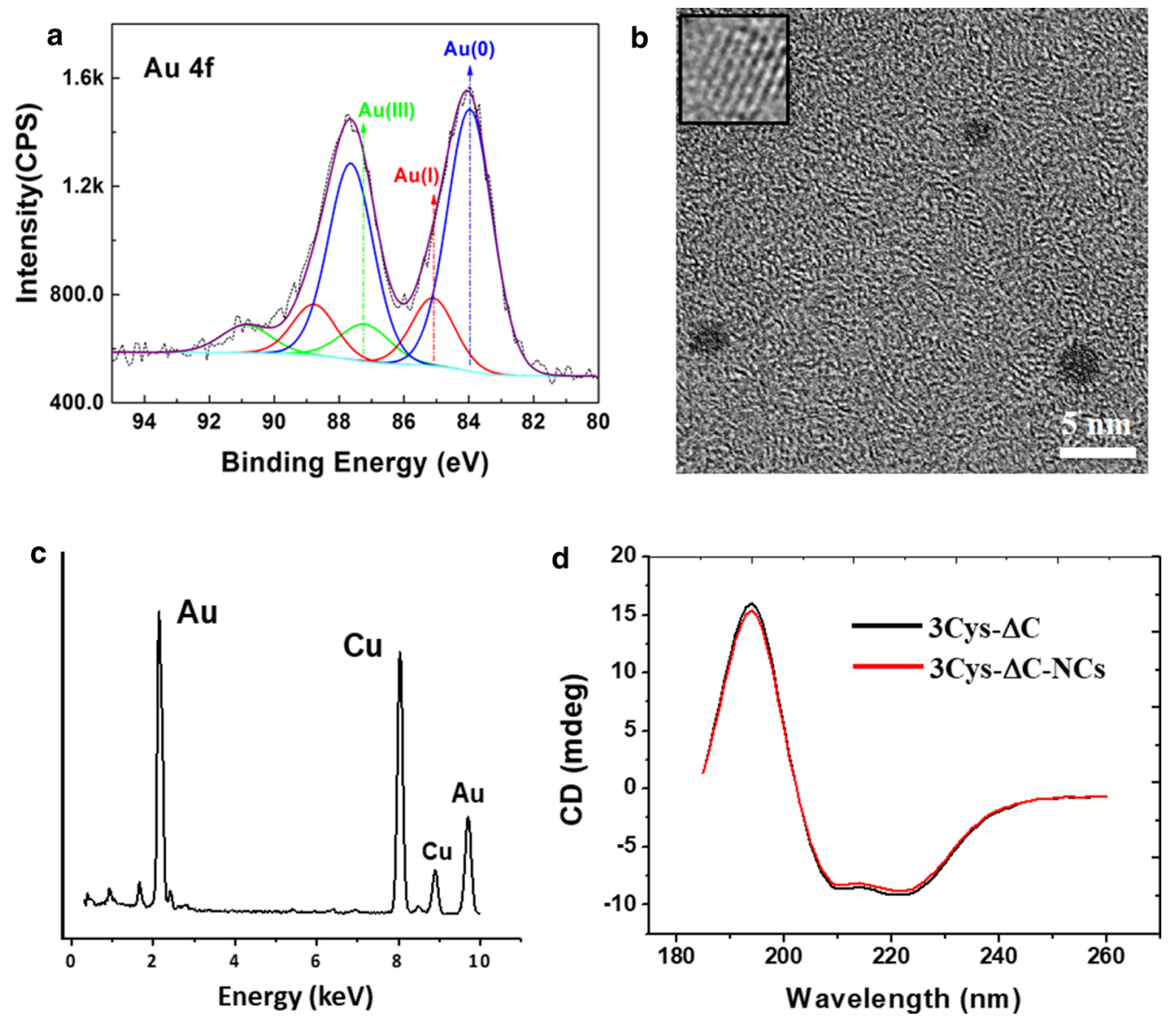

Fig. 3 a XPS spectrum of 3Cys- $\triangle C$-templated Au NCs. $\mathbf{b}$ HTEM image of 3Cys- $\triangle$ C-templated Au NCs. Inset shows lattice fringe of this newly synthesized ferritin-Au NCs composite. $\mathbf{c}$ EDX spectrum of 3Cys- $\triangle C$-templated Au NCs. $\mathbf{d}$ Comparison of CD spectrum of 3Cys- $\Delta C$-templated Au NCs with that of wt HuFtMt

the presence of gold (Fig. 3c). The CD spectrum of the 3 Cys- $\Delta$ C-templated Au NCs was nearly overlapped with that of protein template alone (Fig. 3d), indicating that protein secondary structure remained almost unchanged upon incorporation of small Au NCs into the intrasubunit. Therefore, the genetically modified ferroxidase center containing cysteine residues could be developed into a compartment to synthesize Au NCs. Based on these results, it is worth noting that $\mathrm{Au}$ ions preferentially bind to cysteine residues in protein, and such property can be utilized for directing the site of Au NCs formed with protein as a biotemplate.

Compared with previously reported protein-templated NCs, 3Cys- $\Delta$ C-stabilized $\mathrm{Au} \mathrm{NCs}$ is endowed with an outstanding feature as shown in Fig. 4a; namely, with continuous reduction by excess $\mathrm{NaOH}$ at $37{ }^{\circ} \mathrm{C}$, the fluorescence intensity remains stable. However, for reported BSA or $\beta$-lactoglobulin their solution $\mathrm{pH}$ must be tuned back to neutral on time to terminate the reduction process, otherwise the formed NCs will grow into larger nanoparticles, leading to loss of fluorescence [29, 32]. Indeed, the fluorescence of $\beta$-lactoglobulin stablized $\mathrm{Au}$ NCs usually exhibits a different kinetic curve from 3 Cys- $\Delta C$-stabilized Au NCs as shown in Fig. 4a, namely, it initially increases to a maximum value at about $20 \mathrm{~h}$, followed by decay. We believe that the higher stability of the 3Cys- $\Delta \mathrm{C}$-templated Au NCs stems from the prevention of the excessive growth of $\mathrm{Au} \mathrm{NCs}$ by the size-constrained ferroxidase centers which are buried within four $\alpha$-helix bundle (Fig. 4b). Consistent with this view, it was observed that the fluorescence of $3 C y s-\Delta C$-stabilized $A u$ $\mathrm{NCs}$ sharply decreased at $8 \mathrm{~h}$ (Additional file 1: Figure S6) upon increasing solution $\mathrm{pH}$ to 13.5 , a value which can denature four- $\alpha$-helix bundle. Further support for this view comes from fluorescence results when wt HuFtMt was used as a biotemplate for preparation of Au NCs. The mixture of wt $\mathrm{HuFtMt}$ with $\mathrm{HAuCl}_{4}$ exhibited a red color, with extremely weak fluorescence under UV-light as confirmed by its fluorescence spectrum (Fig. 2C1). This is most likely derived from the formation of larger-sized 


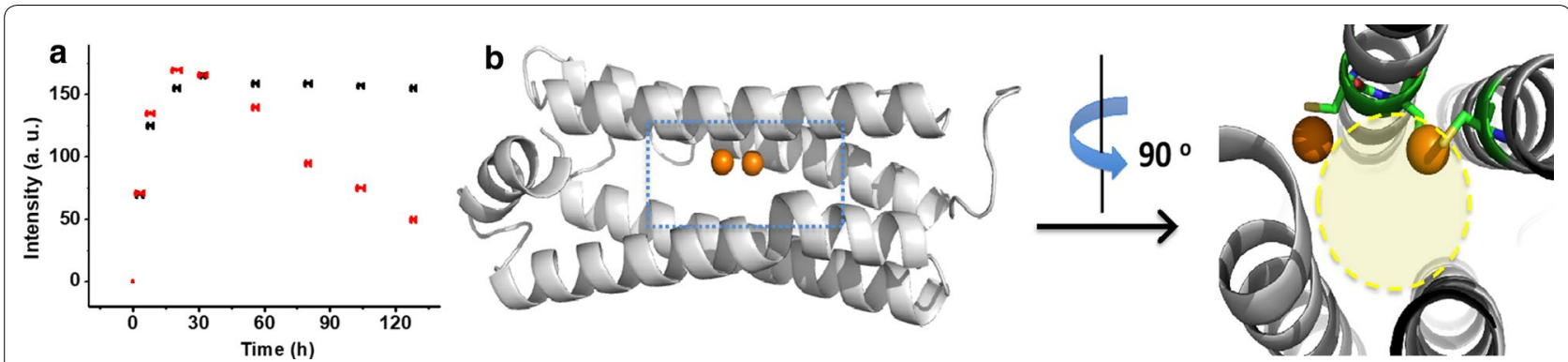

Fig. 4 a The fluorescence intensity of 3 Cys- $\triangle C$-templated Au NCs (black) and $\beta$-lactoglobulin-templated Au NCs (red) as a function of reacting time under basic conditions. b The two Au binding sites are located within four a-helix bundle of $3 C y s-\triangle C$ observed from side-view and top-view, respectively, and such a size-constrained microenvironment is necessary for preparation of Au NCs

$\mathrm{Au}$ particles in the presence of wt HuFtMt. Indeed, the UV-vis spectrum of the mixture of wt HuFtMt with $\mathrm{Au}$ ions exhibits a peak at $520 \mathrm{~nm}$ (Fig. 2C1, inset), which is characteristic of the larger-sized Au particles rather than NCs $[39,40]$. This result is not surprising. As shown in Additional file 1: Figure S7A, three Au ions-coordinated Cys130 residues are located at the ferritin threefold channel (a relatively unconstrained microenvironment) [41], facilitating the excessive growth of Au NCs (Additional file 1: Figure S7B), thereby losing luminescent property. These findings emphasize the crucial role of the sizeconstrained domain such as the ferroxidase center buried within the intrasubunit in Au NCs synthesis.

\section{Imaging ability of 3 Cys- $\Delta C$-stabilized Au NCs}

To increase the storage stability of $3 C y s-\Delta C$-stabilized $\mathrm{Au} \mathrm{NCs}$ while terminating the reducing reaction of $\mathrm{HAuCl}_{4}$ at basic conditions, the solution $\mathrm{pH}$ was adjusted back to $\sim 7.0$ by drop addition of $1 \mathrm{M}$ acetic acid according to our reported method [32]. After negatively stained by uranyl acetate, the intact protein cage of 3 Cys- $\Delta$ C-stabilized Au NCs was clearly visible as a white circles (Additional file 1: Figure S8A), indicating that ferritin nanocage is highly robust and can withstand the basic conditions used for preparation of Au NCs. Having thus incorporated Au NCs into the intrasubunit interfaces without perturbing the ferritin shell-like structure, we sought to identify the ability of 3 Cys $-\triangle C$-Au NCs to act as an imaging agent in vitro and in vivo. First, we incubated $3 C y s-\Delta C$ and $3 C y s-$ $\triangle \mathrm{C}$-stabilized $\mathrm{Au} \mathrm{NCs}$ with HepG2 cells, respectively. PBS buffer treated cells were set as control. As shown in Fig. 5a, even three samples displayed similar cell morphology in bright field, only 3 Cys- $\Delta$ C-stabilized $A u$ $\mathrm{NCs}$ incubated cells showed luminescence within the cytoplasm, which proved the fluorescence stability of ferritin stabilized Au NCs in vitro. It is worth mentioning that no obvious change of cell survival rate appeared after being incubated with $3 \mathrm{Cys}-\Delta \mathrm{C}$-stabilized $\mathrm{Au} \mathrm{NCs}$ at the concentration below $50 \mu \mathrm{M}$ (Fig. 5b). Thus, 3Cys$\Delta \mathrm{C}$-stabilized Au NCs could be used safely as a bioimaging agent for cells.

Fluorescent imaging in vivo is of essential importance for practical applications, and thus we further investigated the bioimaging of $3 C y s-\Delta C$-templated $\mathrm{Au}$ NCs by utilizing Caenorhabditis elegans as an animal model (C. elegans is a kind of well-studied nematode with well-defined anatomy) [42, 43]. A series of worms at different cultivating times were fixed on glass slides and observed by laser confocal mircoscopy. As shown in Fig. 5c, the worms treated with two negative control samples (only $E$. coli or the complex of $E$. coli and HuFtMt mutant) showed no luminescence. Oppositely, upon treatment of the worms with the ferritin-Au NCs added E. coli, there existed enriching fluorescence along with the worms' morphology from 30 to $50 \mathrm{~h}$. After $70 \mathrm{~h}$, the Au NCs excreted gradually, with luminescence decreasing (Additional file 1: Figure S9). For C. elegans, with short life-cycles, the ferritin$\mathrm{Au}$ NCs composite exhibits fluorescence with high stability and comparably longer storage time. To verify the synthesized dye distribution, we detected a worm sample at the fluorescent peak by confocal microscopy. According to Fig. 5c, the ferritin-Au NCs were clearly observed in the intestines, with luminescence gathered. Differently, worms fed with only $E$. coli, complex of 3 Cys $-\Delta C$ and $E$. coli showed no luminescence at all. On the other hand, worms were free living upon treatment with 3Cys- $\Delta$ C-stabilized Au NCs (Fig. 5d), indicating that the as-prepared $\mathrm{Au}$ NCs are safe in nature. These results demonstrate that $3 \mathrm{Cys}-\Delta \mathrm{C}$-stabilized Au NCs could be absorbed by cells and $C$. elegans, while maintaining their stable fluorescence in vitro and in vivo even against complex environment. Thus, 3 Cys $-\Delta C$ stabilized $\mathrm{Au}$ NCs could be developed into a new class of imaging agents. 

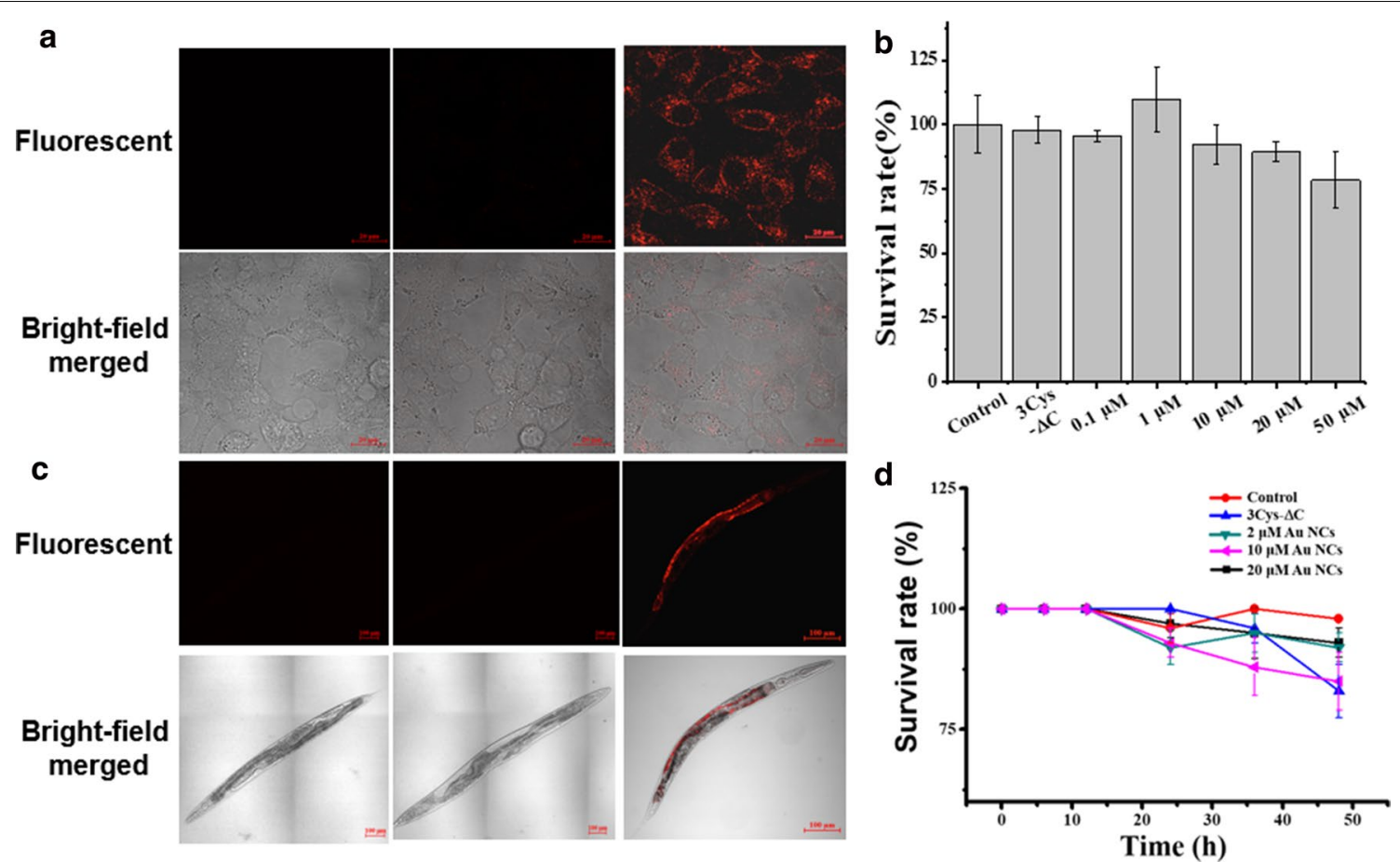

Fig. 5 a Images of buffer as control, $3 C y s-\Delta C$ and $3 C y s-\Delta C-A u N C$ s treated HepG2 cells. Fluorescent and bright-field merged images were made by confocal microscopy. $\mathbf{b}$ Survival rate of cells treated with control buffer, $3 C y s-\triangle C$ and $3 C y s-\triangle C$-Au NCs at differential concentrations. $\mathbf{c}$ Images of E. coli alone, complex of 3Cys- $\triangle C$ and E. coli, and complex of 3Cys- $\triangle C$-Au NCs and E. coli in C. elegans. Fluorescent and bright-field merged images were made by confocal microscopy. $\mathbf{d}$ Survival rate of worms treated with control E. coli, $3 C y s-\Delta C$ and $3 C y s-\Delta C$-Au NCs at differential concentrations

\section{Utilization for hybrid nanomaterials}

The above observation raises an interesting question as to whether the intrinsic cavity of $3 C y s-\Delta C$-stabilized $A u$ $\mathrm{NCs}$ is still able to be used for iron mineralization after $\mathrm{Au}$ NCs occupy the inherent ferroxidase center located within the intrasubunit interfaces. To answer this question, we used the 3Cys- $\Delta \mathrm{C}$-Au NCs composite to fabricate iron cores within the inner cavity by aerobically adding $500 \mathrm{Fe}(\mathrm{II})$ per protein shell to $3 \mathrm{Cys}-\Delta \mathrm{C}$-Au NCs solutions in five successive increments of $100 \mathrm{Fe}(\mathrm{II})$ at intervals of $30 \mathrm{~min}$, followed by standing overnight based on our reported method [44]. TEM analyses revealed the formation of the electron-dense mineral cores with a diameter of 4-6 nm (Fig. 6a). Further energy-dispersive $\mathrm{X}$-ray (EDX) analysis confirmed the presence of iron within the mineral cores (Fig. 6b). Simultaneously, EDX also revealed the presence of $\mathrm{Au}$, which is derived from $\mathrm{Au}$ NCs located within the intrasubunit. After negatively stained by uranyl acetate, it was observed that iron cores are well-distributed within ferritin shell (Fig. 6c). As expected, EDX analyses revealed the co-existence of iron, gold and uranium in the sample (Fig. 6d). Thus, it appears that incorporation of $\mathrm{Au} \mathrm{NCs}$ into its intrasubunit does not interfere with the formation of iron cores within the ferritin cavity. These findings raise the possibility that ferritin nanocage can be developed into a platform which are able to package two different types of inorganic nanomaterials together into a new class of hybrid nanomaterials presented in this work.

Except for synthesis of inorganic nanoparticles, ferritin has been also explored as a vehicle for encapsulation of drug or bioactive nutrient by taking advantage of the reversible dissociation and reassembly characteristic of apoferritin controlled by $\mathrm{pH}$ values as demonstrated by our and other research groups [45-47]. To shed light on effect of the formation of $\mathrm{Au} \mathrm{NCs}$ within the intrasubunit interface on the ability of ferritin to trap guest molecules within the cavity, we mixed curcumin with $3 C y s-\Delta C$ templated $\mathrm{Au} \mathrm{NCs}$ at basic conditions, and then adjusted solution $\mathrm{pH}$ back to neutrality. It was observed that encapsulation of curcumin within ferritin cavity resulted in a color change from light yellow to deep yellow (Fig. 7c, inset). The UV-vis spectrum of the sample exhibits a new visible maximal absorption at $\sim 420 \mathrm{~nm}$ which is characteristic of curcumin (Fig. 7a). TEM analyses revealed that black uranium-containing cores were formed in the cavity (Additional file 1: Figure S8B) with a control sample (3Cys- $\Delta$ C-Au NCs composite alone) due to uranium diffusing into the ferritin cavity via channels after being negatively stained with uranyl acetate [44]. In 

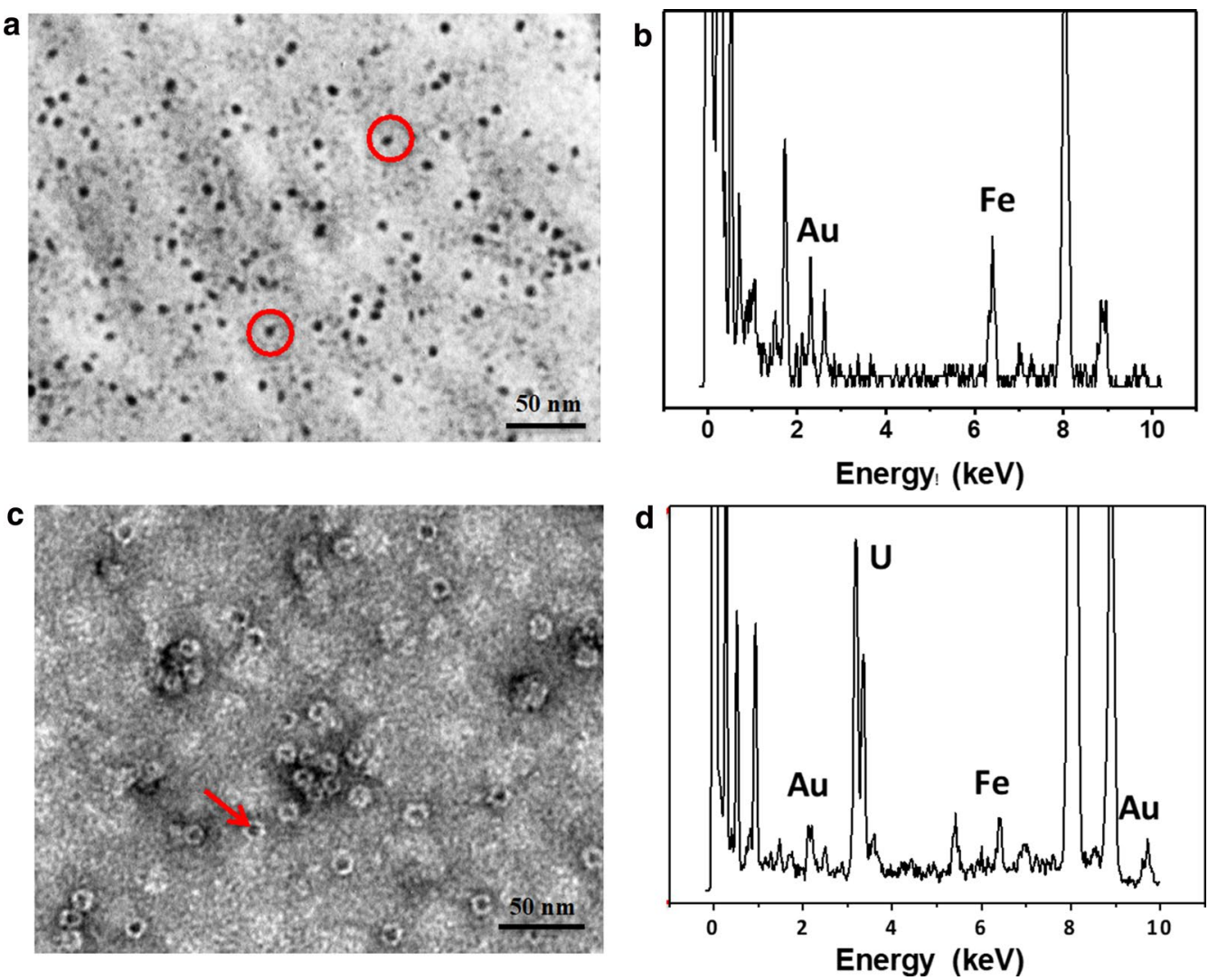

Fig. 6 a TEM image and $\mathbf{b}$ EDX spectrum of iron cores formed within the cavity of the 3 Cys- $\triangle C$-templated Au NCs composite. $\mathbf{c} T E M$ image and $\mathbf{d}$ EDX spectrum of iron cores formed within the cavity of the $3 C y s-\Delta C$-templated Au NCs composite upon negatively stained with uranyl acetate

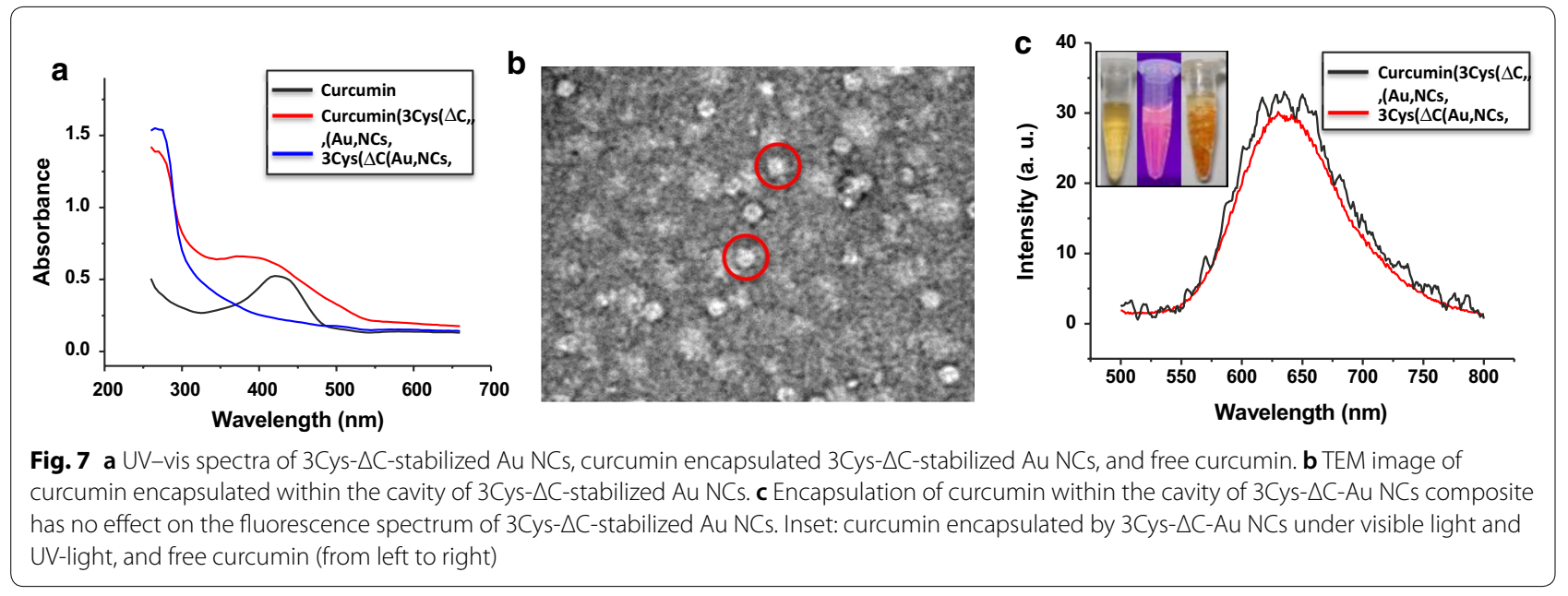

contrast, treatment of the ferritin-Au NCs with curcumin resulted in disappearance of the above discrete electron dense cores; instead, white nanoparticles were visualized (Fig. 7b) under the same experimental conditions, demonstrating that curcumin molecules were successfully trapped within the protein inner cavity. Interestingly, the fluorescent property of $3 \mathrm{Cys}-\Delta \mathrm{C}$-templated $\mathrm{Au}$ NCs maintains unchanged upon curcumin encapsulation (Fig. 7c), again demonstrating that the existence of encapsulated cargo such as curcumin within ferritin shell 
hardly interferes with the fluorescent property of Au NCs buried within the intrasubunit, and vice versa. This is most likely derived from the fact that curcumin and $\mathrm{Au}$ NCs are physically separated within single ferritin molecule. To gain insights into whether the decorated protein shell with Au NCs could improve the thermal and photo stability of curcumin, we further investigated the degradation kinetics of curcumin encapsulated within the ferritin-Au NCs composite upon treatment with heating and light, respectively, with free curcumin as control. As expected, free curcumin is unstable and about $60 \%$ of free curcumin was degraded in 5 min upon thermal treatment (Additional file 1: Figure S10A). In contrast, curcumin encapsulated within ferritin cavity became much stable, and almost no degradation occurred under identical experimental conditions (Additional file 1: Figure S10B). Similarly, we found that encapsulation of curcumin by the ferritin-Au NCs composite can also pronouncedly improve its photo stability (Additional file 1: Figure S10C and S10D).

In conclusion, we built a specific compartment for fabrication of $\mathrm{Au} \mathrm{NCs}$ by re-designing the intrasubunit interfaces of ferritin nanocage, resulting in the site-directed synthesis of Au NCs with protein as a biotemplate. The as-prepared Au NCs in protein shell hardly interferes with the ability of ferritin to either grow iron cores or encapsulate bioactive molecules within the protein cavity. Thus, we can incorporate two different types of nanoparticles into a single protein nanocage. These findings open a new way to prepare 'all-in-one' nanoparticles or nanostructures. Since the intrasubunit interface occurs in nearly all of simple proteins or multisubunit protein architectures, our engineering approach should, in principle, be applicable to these proteins. This would lead to the generation of a variety of fluorescent hybrid nanomaterials.

\section{Additional file}

Additional file 1: Figure S1. Four intersubunit interfaces of ferritin: A) The $C_{4}$ interface. B) The $C_{3}$ interface. C) The $C_{2}$ interface. D) The $C_{3}-C_{4}$ interface which is located between the $C_{3}$ and $C_{4}$ axes. Figure $\mathbf{S 2}$. The schematic diagram of the putative ferroxidase center buried inside four a-helix bundle of human mitochondria ferritin, which are composed of seven conserved amino acid residues. Figure S3. Characterization of three HuFtMt mutants $\triangle C, 2 C y s-\Delta C$ and $3 C y s-\Delta C$ with wt HuFtMt as control by (A) SDS PAGE, (B) Native PAGE, (C) Fluorescence spectra and (D) TEM images. Characters a, b and c correspond to $\Delta C, 2 C y s-\Delta C$ and $3 C y s-\Delta C$ mutants, respectively. Scale bars represent $50 \mathrm{~nm}$. Figure $\mathbf{S 4}$. Fluorescence excitation spectrum of 3Cys- $\Delta$ C stabilized Au NCs with $650 \mathrm{~nm}$ as the maximum emission wavelength. Figure S5. TEM view of 3Cys- $\Delta C$ stabilized Au NCs. A) The zoom-out TEM view of $3 C$ cys- $\Delta C$ stabilized Au $N C s$ under basic conditions. The inset image was the distribution 3Cys- $\Delta C$ stabilized Au NCs according to their size. B) TEM view of $3 C y s-\Delta C$ stabilized Au NCs once pH was adjusted back to neutral condition. Figure $\mathbf{S 6}$.
Fluorescence spectra of 3Cys- $\triangle \mathrm{C}$-templated Au NCs at $3 \mathrm{~h}$ and $8 \mathrm{~h}$ after adjusting solution $\mathrm{pH}$ to 13.5. Figure S7. A) The three Au ions bound at the 3-fold channels of wide-type HuFtMt. Three Cys130 are involved in coordination with the three Au ions, respectively, which are highlighted in red. B) The TEM view of Au NCs stabilized by wide-type HuFtMt. Figure S8. A) TEM image of $3 C y s-\triangle C$-templated Au NCs after the solution $\mathrm{pH}$ was adjusted back to neutral by drop addition of $1 \mathrm{M}$ acetic acid. B) EDX spectrum of the inner cavity of 3 Cys- $\Delta C$-templated Au NCs composite, where was negatively stained by uranyl acetate. Figure $\mathbf{S 9}$. Fluorescent microscopy images of $C$. elegans treated with $3 C y s-\Delta C$-templated $A u$ $\mathrm{NCs}$ for different times. Figure S10. Kinetic decay UV-vis spectra of free curcumin (A) and curcumin encapsulated 3Cys- $\triangle$ C-Au NCs (B) due to heating treatment. Kinetic decay UV-vis spectrum of free curcumin (C) and curcumin encapsulated 3 Cys- $\triangle C$-Au NCs (D) due to exposure to light. Table S1. X-ray diffraction data collection and processing statistics.

\section{Authors' contributions}

GZ designed the study, supervised the project. JZ conceived and carried out experiments and analysed data. BZ, XZ and PA assisted in the characterization of ferritin and nanoclusters. All authors wrote the final manuscript. All authors read and approved the final manuscript.

\section{Funding}

The authors gratefully acknowledge the National Natural Science Foundation of China (No. 31730069) and the Initiative Postdocs Supporting Program of China (No. BX201700284).

\section{Competing interests}

The authors declare that they have no competing interests.

\section{Author details}

${ }^{1}$ Beijing Advanced Innovation Center for Food Nutrition and Human Health, College of Food Science \& Nutritional Engineering, Beijing Key Laboratory of Functional Food from Plant Resources, China Agricultural University, Beijing 100083, China. ${ }^{2}$ Department of Molecular and Translational Medicine, University of Brescia, Viale Europa 11, 25123 Brescia, Italy.

Received: 2 March 2019 Accepted: 26 June 2019

Published online: 05 July 2019

\section{References}

1. Longstreet AR, Mcquade DT. Organic reaction systems: using microcapsules and microreactors to perform chemical synthesis. Acc Chem Res. 2013;46:327-38.

2. Fischlechner M, Schaerli Y, Mohamed MF, Patil S, Abell C, Hollfelder F. Evolution of enzyme catalysts caged in biomimetic gel-shell beads. Nat Chem. 2014;6:791-6.

3. Uchida M, Klem MT, Allen M, Suci P, Flenniken M, Gillitzer E, Varpness Z, Liepold LO, Young M, Douglas T. Biological containers: protein cages as multifunctional nanoplatforms. Adv Mater. 2010;19:1025-42.

4. Zang J, Chen $\mathrm{H}$, Zhao G, Wang F, Ren F. Ferritin cage for encapsulation and delivery of bioactive nutrients: from structure, property to applications. Crit Rev Food Sci Nutr. 2017;57:3673-84.

5. Royle SJ. The cellular functions of clathrin. Cell Mol Life Sci. 2006;63:1823-32.

6. Canady MA, Larson SB, Day J, McPherson A. Crystal structure of turnip yellow mosaic virus. Nat Struct Mol Biol. 1996;3:771.

7. Tanaka S, Kerfeld CA, Sawaya MR, Cai F, Heinhorst S, Cannon GC, Yeates TO. Atomic-level models of the bacterial carboxysome shell. Science. 2008;319:1083-6.

8. Zhao G, Ceci P, Ilari A, Giangiacomo L, Laue TM, Chiancone E, Chasteen ND. Iron and hydrogen peroxide detoxification properties of DNAbinding protein from starved cells. A ferritin-like DNA-binding protein of Escherichia coli. J Biol Chem. 2002;277:27689-96.

9. Fan K, Cao C, Pan Y, Lu D, Yang D, Feng J, Song L, Liang M, Yan X. Magnetoferritin nanoparticles for targeting and visualizing tumour tissues. Nat Nanotechnol. 2012;7:459-64. 
10. Li JY, Paragas N, Ned RM, Qiu A, Viltard M, Leete T, Drexler IR, Chen X, Sanna-Cherchi S, Mohammed F, Williams D, Lin CS, Schmidt-Ott KM, Andrews NC. Scara5 is a ferritin receptor mediating non-transferrin iron delivery. Dev Cell. 2009;16:35-46.

11. Liao X, Yun S, Zhao G. function, and nutrition of phytoferritin: a newly functional factor for iron supplement. Crit Rev Food Sci Nutr. 2014;54:1342-52.

12. Huang $P$, Rong $P$, Jin A, Yan X, Zhang MG, Lin J, Hu H, Wang Z, Yue X, Li W, Niu G, Zeng W, Wang W, Zhou K, Chen X. Dye-loaded ferritin nanocages for multimodal imaging and photothermal therapy. Adv Mater. 2014;26:6401-8.

13. Domínguez-Vera JM, Colacio E. Nanoparticles of prussian blue ferritin: a new route for obtaining nanomaterials. Inorg Chem. 2003;42:6983-5.

14. He D, Marles-Wright J. Ferritin family proteins and their use in bionanotechnology. N Biotechnol. 2015;32:651-7.

15. Harrison PM, Arosio P. The ferritins: molecular properties, iron storage function and cellular regulation. Biochim Biophys Acta Bioenergy. 1996;1275:161-203.

16. Bou-Abdallah F, Zhao G, Biasiotto G, Poli M, Arosio P, Chasteen ND. Facilitated diffusion of iron(II) and dioxygen substrates into human $\mathrm{H}$-chain ferritin. A fluorescence and absorbance study employing the ferroxidase center. J Am Chem Soc. 2008;130:17801-11.

17. Huard DJ, Kane KM, Tezcan FA. Re-engineering protein interfaces yields copper-inducible ferritin cage assembly. Nat Chem Biol. 2013;9:169-76.

18. Zhang S, Zang J, Wang W, Chen H, Zhang X, Wang F, Wang H, Zhao G. Conversion of the native 24-mer ferritin nanocage into its non-native 16-mer analogue by insertion of extra amino acid residues. Angew Chem Int Ed. 2016;55:16064-70.

19. Zhang S, Zang J, Zhang X, Chen H, Mikami B, Zhao G. "Silent" amino acid residues at key subunit interfaces regulate the geometry of protein nanocages. ACS Nano. 2016:10:10382-8.

20. Jeon JO, Kim S, Choi E, Shin K, Cha K, So I, Kim S, Jun E, Kim D, Ahn HJ, Lee B, Lee S, Kim I. Designed nanocage displaying ligand-specific Peptide bunches for high affinity and biological activity. ACS Nano. 2013;7:7462-71

21. Kang YJ, Park DC, Shin H, Park J, Kang S. Incorporation of thrombin cleavage peptide into a protein cage for constructing a proteaseresponsive multifunctional delivery nanoplatform. Biomacromolecules. 2012;13:4057-64.

22. Lin X, Xie J, Zhu L, Lee S, Niu G, Ma Y, Kim K, Chen X. Hybrid ferritin nanoparticles as activatable probes for tumor imaging. Angew Chem Int Ed. 2011;50:1607-10.

23. Choi KM, Choi SH, Jeon H, Kim IS, Ahn HJ. Chimeric capsid protein as a nanocarrier for siRNA delivery: stability and cellular uptake of encapsulated siRNA. ACS Nano. 2011;5:8690-9.

24. Ma-Ham A, Wu H, Wang J, Kang X, Zhang Y, Lin Y. Apoferritin-based nanomedicine platform for drug delivery: equilibrium binding study of daunomycin with DNA. J Mater Chem. 2011;21:8700.

25. Liang M, Fan K, Zhou M, Duan D, Zheng J, Yang D, Feng J, Yan X. H-ferritinnanocaged doxorubicin nanoparticles specifically target and kill tumors with a single-dose injection. Proc Natl Acad Sci. 2014;111:14900-5.

26. Kwak K, Choi W, Tang Q, Kim M, Lee Y, Jiang DE, Lee D. A molecule-like PtAu24(SC6H13)18 nanocluster as an electrocatalyst for hydrogen production. Nat Commun. 2017;8:14723.

27. Antonello S, Dainese T, Pan F, Rissanen K, Maran F. Electrocrystallization of monolayer-protected gold clusters: opening the door to quality, quantity, and new structures. J Am Chem Soc. 2017;139:4168-74.

28. Chen Y, Montana DM, Wei H, Cordero JM, Schneider M, Guevel XL, Chen $\mathrm{O}$, Bruns OT, Bawendi MG. Shortwave infrared in vivo imaging with gold nanoclusters. Nano Lett. 2017:17:6330-4.

29. Xie J, Zheng Y, Ying J. Protein-directed synthesis of highly fluorescent gold nanoclusters. J Am Chem Soc. 2009;131:888-9.

30. Wei H, Wang Z, Zhang J, House S, Gao YG, Yang L, Robinson H, Tan $\mathrm{LH}$, Xing $\mathrm{H}$, Hou C, Robertson IM, Zuo JM, Lu Y. New aspects of the metal-insulator transition in single-domain vanadium dioxide nanobeams. Nat Nanotechnol. 2011;6:93-7.

31. Qiao J, Mu X, Qi L, Deng J, Mao L. Folic acid-functionalized fluorescent gold nanoclusters with polymers as linkers for cancer cell imaging. Chem Commun. 2013:49:8030-2.

32. Zang J, Li C, Zhou K, Dong H, Chen B, Wang F, Zhao G. Nanomolar Hg ${ }^{2+}$ detection using $\beta$-lactoglobulin-stabilized fluorescent gold nanoclusters in beverage and biological media. Anal Chem. 2016;88:10275-83.

33. Wang Y, Chen JT, Yan XP. Fabrication of transferrin functionalized gold nanoclusters/graphene oxide nanocomposite for turn-on near-infrared fluorescent bioimaging of cancer cells and small animals. Anal Chem. 2013;85:2529-35.

34. Lawson DM, Artymiuk PJ, Yewdall SJ, Smith JMA, Livingstone JC, Treffry A, Luzzago A, Levi S, Arosio P, Cesareni G, Thomas CD, Shaw WV, Harrison PM. Solving the structure of human $\mathrm{H}$ ferritin by genetically engineering intermolecular crystal contacts. Nature. 1991;349:541-4.

35. Hempstead PD, Yewdall SJ, Fernie AR, Lawson DM, Artymiuk PJ, Rice DW, Ford GC, Harrison PM. Comparison of the three-dimensional structures of recombinant human $\mathrm{H}$ and horse $\mathrm{L}$ ferritins at high resolution. J Mol Biol. 1997;268:424-48

36. d'Estaintot BL, Santambrogio P, Granier T, Gallois B, Chevalier JM, Preigoux G, Levi S, Arosio P. Crystal structure and biochemical properties of the human mitochondrial ferritin and its mutant Ser144Ala. J Mol Biol. 2004:340:277-93.

37. Ebrahimi KH, Hagedoorn P, Hagen WR. Unity in the biochemistry of the iron-storage proteins ferritin and bacterioferritin. Chem Rev. 2015;115:295-326.

38. Bou-Abdallah F. The iron redox and hydrolysis chemistry of the ferritins. Biochim Biophys Acta. 2010;1800:719-31.

39. Halas NJ, Lal S, Link S, Chang W, Natelson D, Hafner JH, Nordlander P. A plethora of plasmonics from the laboratory for nanophotonics at Rice University. Adv Mater. 2012;24:4842-77.

40. Kumar D, Lee SB, Park CH, Kim CS. Impact of ultra-small platinum nanoparticles coating on different morphologies of gold nanostructures for multiple one-pot photo-catalytic environment protection reactions. ACS Appl Mater Interfaces. 2018;10:389-99.

41. Maity B, Abe S, Ueno T. Observation of gold sub-nanocluster nucleation within a crystalline protein cage. Nat Commun. 2017;6:93.

42. Zhang S, Zang J, Chen H, Li M, Xu C, Zhao G. The size flexibility of ferritin nanocage opens a new way to prepare nanomaterials. Small. 2017;13:1701045

43. Chen L, Bai G, Yang S, Yang R, Zhao G, Xu C, Leung W. Encapsulation of curcumin in recombinant human $\mathrm{H}$-chain ferritin increases its watersolubility and stability. Food Res Int. 2014;63:1147.

44. Zhen Z, Tang W, Chen H, Lin X, Todd T, Wang G, Cowger T, Chen X, Xie J. RGD modified apoferritin nanoparticles for efficient drug delivery to tumors. ACS Nano. 2013:6:4830-7.

45. Song B, Zhong Y, Wu S, Chu B, Su Y, He Y. One-dimensional fluorescent silicon nanorods featuring ultrahigh photostability, favorable biocompatibility and excitation wavelength-dependent emission spectra. J Am Chem Soc. 2016;138:4824-31.

46. Ma PA, Xiao HH, Li XX, Li CX, Dai YL, Cheng ZY, Jing XB, Lin J. Rational design of multifunctional upconversion nanocrystals/polymer nanocomposites for cisplatin (IV) delivery and biomedical imaging. Adv Mater. 2013;25:4849-905.

47. Bou-Abdallah F, Santambrogio P, Levi S, Arosio P, Chasteen ND. Unique iron binding and oxidation properties of human mitochondrial ferritin: a comparative analysis with human $\mathrm{H}$-chain ferritin. J Mol Biol. 2005;347:543-54.

\section{Publisher's Note}

Springer Nature remains neutral with regard to jurisdictional claims in published maps and institutional affiliations. 